\title{
Neurosurgeons' Armamentarium for the Management of Refractory Postherpetic Neuralgia: A Systematic Literature Review
}

\author{
Pavlos Texakalidis Muhibullah S. Tora Nicholas M. Boulis \\ Department of Neurosurgery, Emory University School of Medicine, Atlanta, GA, USA
}

\begin{abstract}
Background/Aims: Postherpetic neuralgia (PHN) can be refractory to both medical and minimally invasive treatments. Its complex pathophysiology explains the numerous neurosurgical procedures that have been implemented through the years. Our objective was to summarize all available neurosurgical strategies for the management of resistant PHN and evaluate their respective safety and efficacy outcomes. Methods: A comprehensive systematic review was conducted according to the Preferred Reporting Items for Systematic Reviews and Meta-Analyses (PRISMA) guidelines. $\boldsymbol{R e}$ sults: A total of 38 studies comprising 811 patients with refractory PHN were included. The safety and efficacy of the following procedures were investigated: spinal cord stimulation (SCS), dorsal root entry zone (DREZ) lesioning, intrathecal drug delivery, caudalis DREZ lesioning, dorsal root ganglion (DRG) radiofrequency lesioning, peripheral nerve stimulation, gamma knife surgery, deep brain stimulation, cordotomy, percutaneous radiofrequency rhizotomy and Gasserian ganglion stimulation. Conclusions: There are several available neurosurgical approaches for recalcitrant PHN including neuromodulatory and ablative procedures. It is suggested that patients with resistant PHN undergo minimally invasive procedures first, including SCS, peripheral nerve stimulation or DRG radiofrequency lesioning. More in-
\end{abstract}

vasive procedures should be reserved for refractory cases. Comparative studies are needed in order to construct a PHN neurosurgical management algorithm.

(c) 2019 S. Karger AG, Basel

\section{Introduction}

Postherpetic neuralgia (PHN) is a debilitating neuropathic pain syndrome which is characterized by pain persisting for more than 1-3 months at the site of acute zoster after the rash has healed $[1,2]$. The incidence of PHN following acute zoster infection has been reported in the range of $10-20 \%$, being severer and more prevalent in the elderly [3-5]. The pain in PHN is frequently severe enough to disrupt the quality of lives of otherwise healthy individuals.

PHN pain is frequently characterized by mechanical allodynia while decreased pinprick sensation and paresthesias are also common $[2,5]$. The mechanisms implicated in the development of pain in PHN are complex and involve injury of the peripheral nerves and alterations in the central nervous system signal processing and central sensitization; however, the actual cause of PHN is not totally understood [6]. It has been hypothesized that dam-

\section{KARGER}

() 2019 S. Karger AG, Basel

E-Mail karger@karger.com

www.karger.com/sfn
Pavlos Texakalidis, MD

Department of Neurosurgery, Emory University School of Medicine Woodruff Circle

Atlanta, GA 30322 (USA)

E-Mail Pavlos.texakalidis@emory.edu 
aged peripheral neurons have lower activation thresholds, can discharge without provocation and demonstrate exaggerated responses to normal stimuli. Furthermore, axonal sprouting following nerve injury can lead to spontaneous nerve discharge [7] and formation of new aberrant connections between nonnociceptive large-diameter afferent fibers and central pain transmission neurons [8].

This complex pathophysiology explains the existence of the wide variety of medical and surgical strategies that can potentially manage PHN-related pain. First-line treatments for PHN include, but are not limited to, tricyclic antidepressants, gapapentin, pregabalin and lidocaine patch [9]. However, a handful of patients can be refractory to every medical treatment and need neurological surgeries to manage their pain [10]. The expanded neurosurgical armamentarium for the treatment of recalcitrant PHN includes spinal cord stimulation (SCS), subcutaneous peripheral nerve stimulation, deep brain stimulation (DBS), dorsal root entry zone (DREZ) lesioning, dorsal root ganglion (DRG) stimulation, intrathecal (IT) injection and pump insertion, cordotomy, motor cortex stimulation, gamma knife surgery and caudalis DREZ lesioning/nucleotomy. The aim of this systematic literature review is to summarize all available neurosurgical strategies for the management of resistant $\mathrm{PHN}$ and evaluate their reported safety and efficacy outcomes.

\section{Methods}

Search Strategy and Selection Criteria

This systematic review was conducted in accordance with the Preferred Reporting Items for Systematic Reviews and Meta-Analyses (PRISMA) guidelines [11]. Eligible articles were identified through searches of the PubMed and Cochrane databases up to October 2018 by two independent reviewers (P.T., M.S.T.). The following search algorithm was used: postherpetic neuralgia AND (cordotomy OR cingulotomy OR neurosurgery OR DBS OR deep brain stimulation OR intrathecal OR spinal cord stimulation OR rhizotomy OR motor cortex stimulation OR thalamus OR transcutaneous stimulation OR DREZ OR dorsal root entry zone lesioning OR dorsal root ganglion stimulation). A study was included in this systematic review if it fulfilled the following predefined criteria: (i) randomized controlled trials or prospective or retrospective observational analyses reporting on neurosurgical treatments of refractory PHN, (ii) studies published in English up to October 2018, (iii) studies reporting on pain reduction either with visual analog scale (VAS) scores before and after the procedure (continuous variable) or by using a pain reduction cutoff percentage (categorical variable). Excluded studies met at least one of the following criteria: (i) case reports, (ii) animal studies, (iii) reviews, meta-analyses, letters to the editor or editorials and (iv) studies reporting on patients who underwent 2 or more different neurosurgical procedures at the same time.

\section{Data Extraction}

Two reviewers (P.T., M.S.T.) independently reviewed the included studies and extracted data. All disagreements were resolved with consensus by the addition of a third reviewer (N.M.B.). Data extraction was based on a predefined Excel spreadsheet with the following variables: first author, year of publication, country and institution, years of enrollment, study design and study period, sample size, patient baseline demographics, number of patients who had antiviral therapy during the acute zoster infection and epidural block, medical or surgical treatments that had previously failed, days passed from the acute zoster to the neurosurgical treatment under investigation, affected dermatomes, VAS before and after the procedure, use of medication after the procedure, followup duration, procedure-related complications and additional procedures needed for pain management.

\section{Risk of Bias Assessment}

Risk of bias was assessed by two investigators (P.T., M.S.T.). Nonrandomized trials were evaluated according to the criteria proposed by the Cochrane tool for observational studies (ACROBAT) for the following domains: (i) confounding, (ii) selection, (iii) measurement of interventions, (iv) deviations from intended interventions, (v) missing data, (vi) measurement of outcomes and (vii) selection of the reported result. Studies were assessed as low, moderate or high risk of bias in every domain.

\section{Statistical Synthesis and Analysis}

Descriptive statistics were applied as appropriate. Categorical variables were summarized as frequencies and percentages and continuous variables as mean and standard deviations when available. For studies that reported continuous data as medians and range, the method proposed by Hozo et al. [12] was utilized to convert it to mean and standard deviation.

\section{Results}

\section{Search Results}

Literature search yielded 356 potentially relevant records after duplicates had been removed. After screening titles and abstracts, 55 articles were retrieved for full-text evaluation. Thirty-nine studies met the predetermined eligibility criteria and were included in the systematic review as shown in the PRISMA flow diagram (Fig. 1). Table 1 presents important study and patient features. A detailed assessment of risk of bias is available in the online supplementary Table 1 (for all online suppl. material, see www.karger.com/doi/10.1159/000499476). Postoperative outcomes and baseline patient characteristics for the various neurosurgical approaches for the management of recalcitrant PHN are summarized below (Table 2).

\section{Spinal Cord Stimulation}

Ten studies comprising 243 patients were identified (weighted mean age 58.9 years, $53.1 \%$ male) [13-22]. In
Texakalidis/Tora/Boulis 


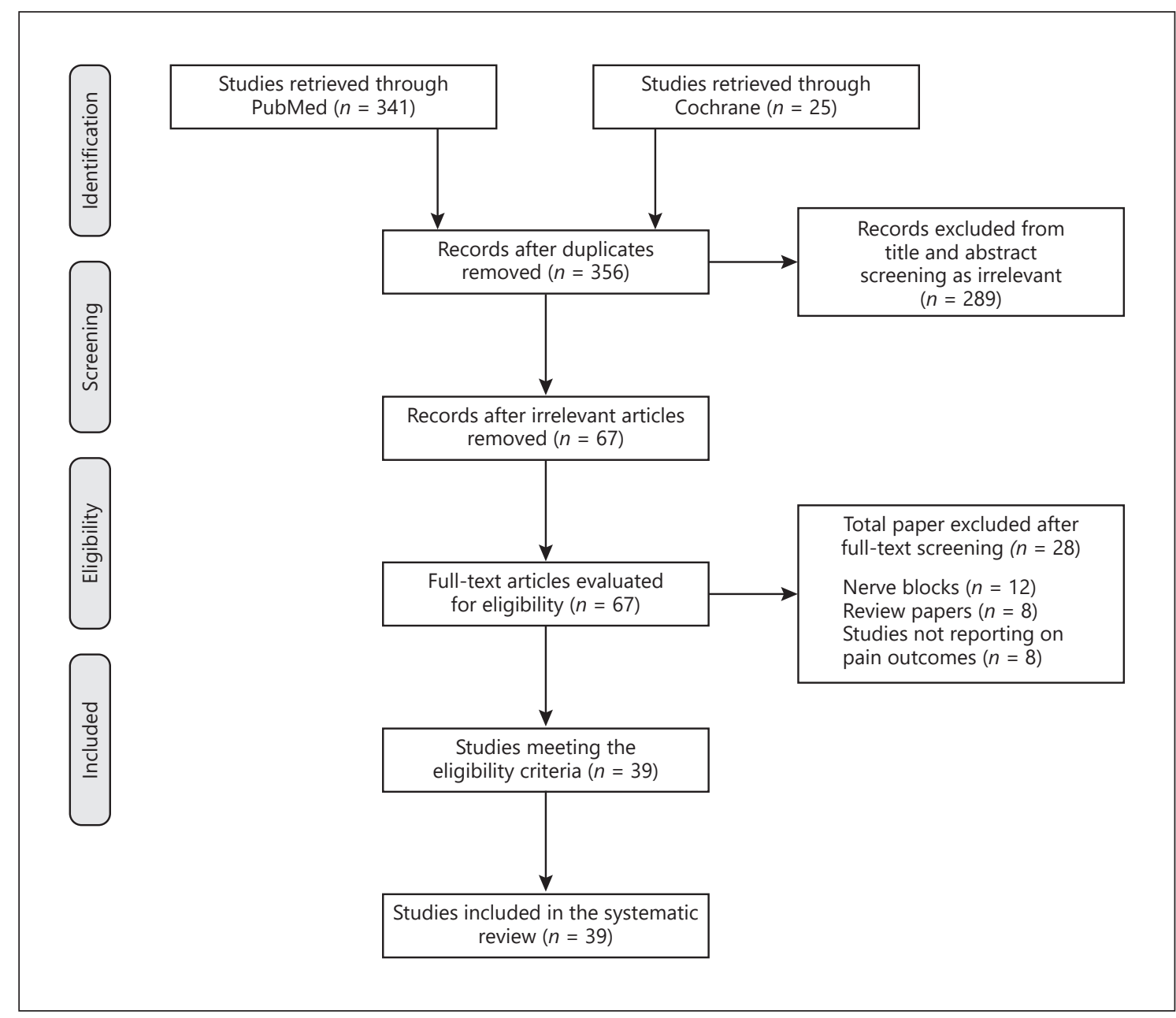

Fig. 1. PRISMA flow diagram.

3 studies with available data, all patients were unsuccessfully treated with antiviral agents, epidural and/or nerve blocks and multiple pain medications including gabapentin, pregabalin, nonsteroidal anti-inflammatory drugs, opioids, antiepileptics and antidepressants [14, 16, 17]. The SCS was performed at the thoracic (81.7\%), cervical (12.3\%), lumbar (2\%) and cervicomedullary junction (4\%) levels after a mean of 17.6 months following zoster onset. Implantation of the SCS devices was performed in a 2-stage procedure only in patients who experienced a successful trial stimulation (86.5\%). The mean VAS before and after the SCS was 7.6 and 2.7 after the long-term follow-up (18.2 months). Pain reduction $>50 \%$ was documented in $41.1 \%(88 / 214)$ of patients from 6 studies with relevant data. Interestingly, the pain-reducing effect of SCS was consistent both in studies with short- (less than a year) and long-term follow-up. There was a dramatic decrease in patients (94.7\%, 18/19 patients) who required opioids following the SCS in the study by Harke et al. [21]. However, in another study, no change between the preand postprocedural analgesic medication dose was reported in the 21 patients who observed analgesic effects of the SCS [14]. No major complications were reported other than transient hypotension (3/14 patients), urinary retention (7/14 patients) and a snapped quadripolar lead where the procedure had to be repeated $[14,17]$.

\section{DREZ Lesioning}

Six studies reporting on DREZ lesioning for the treatment of refractory PHN were identified, including 84 patients overall [23-28]. The weighted mean age was 70 years $(66.7 \%$ male) from studies with available data. The procedure was performed after a mean of 3.6 years following zoster onset at the thoracic (79.2\%) and cervical 


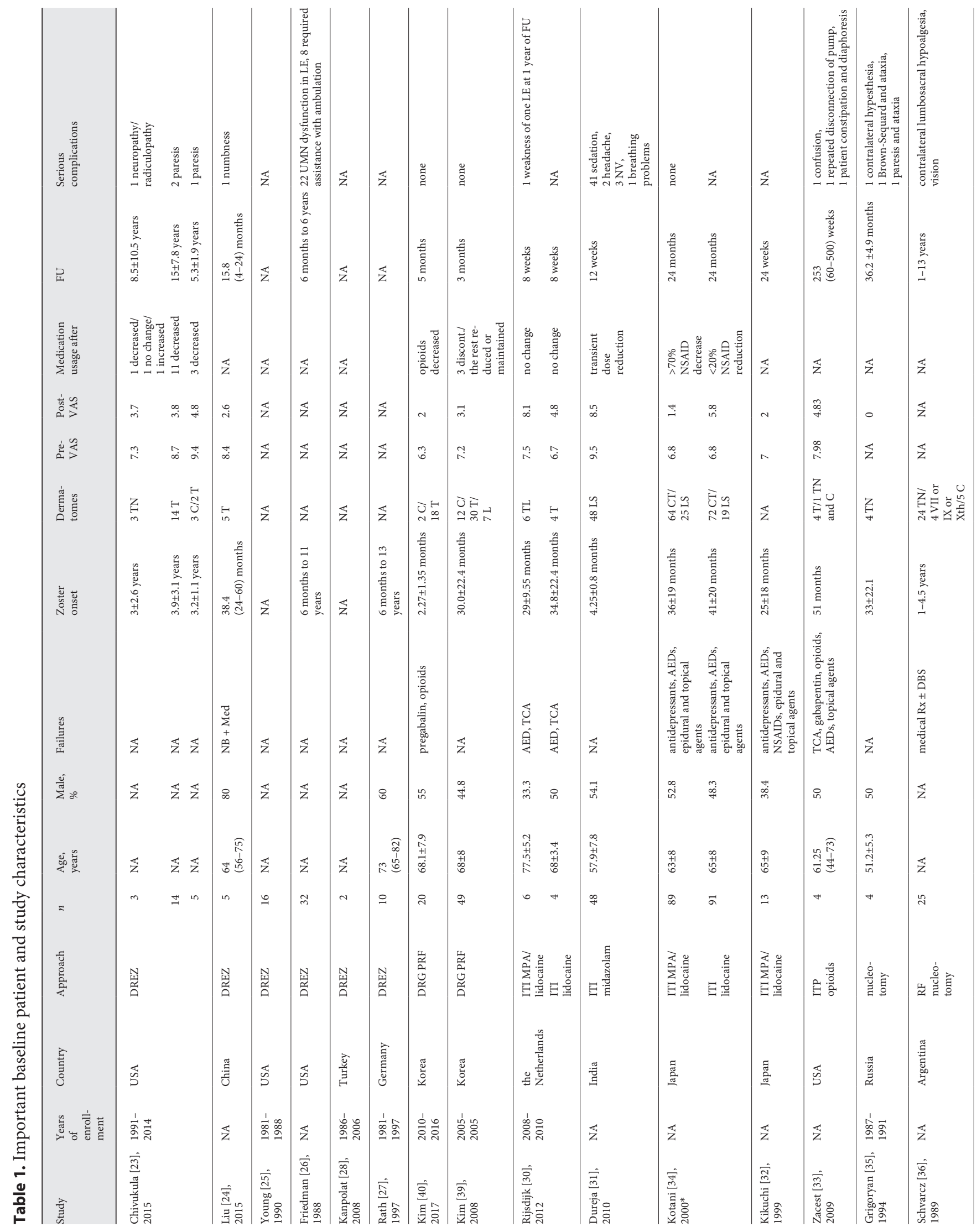




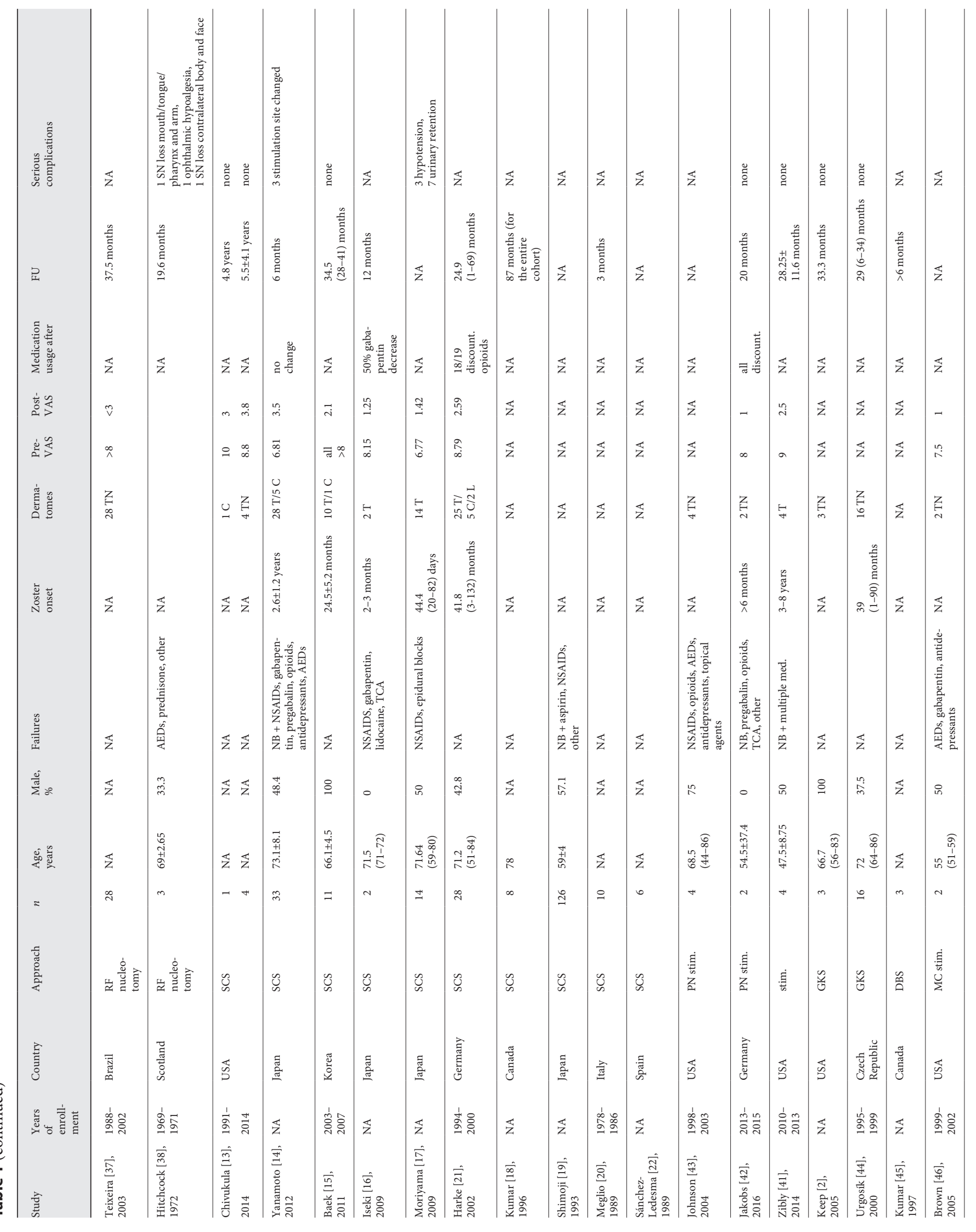




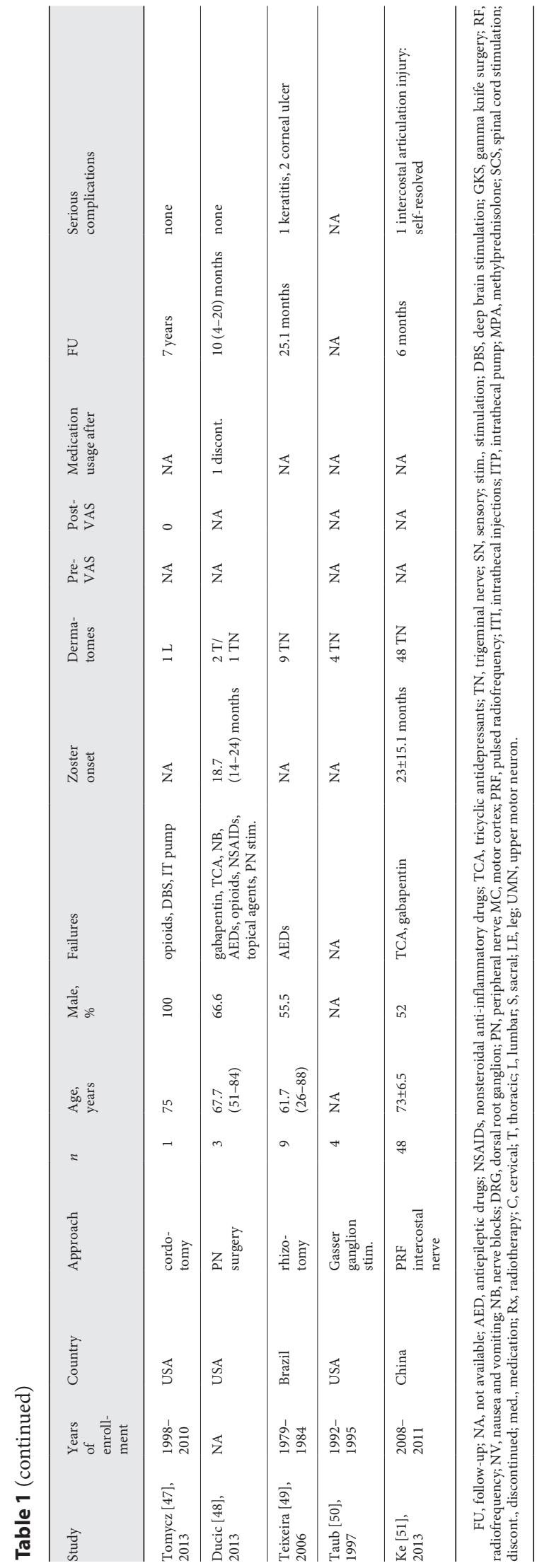

(20.8\%) levels. The weighted mean VAS score before the procedure was 8.7 whereas after the long-term follow-up of 10.1 years it was 3.7. A total of 26 of 65 patients (40\%) achieved more than $50 \%$ pain reduction in the 5 studies with available data [24, 25, 27-29]. Interestingly, 30.9\% of patients $(n=13 / 42)$ reported a change in the pain character after the DREZ lesioning procedure from burning to aching/throbbing pain or cold sensation. A total of 14 of 19 patients $(73.7 \%)$ had their medication reduced or stopped after the surgery. During the postoperative period, 25 of $56(44.6 \%)$ patients developed motor deficits and 1 numbness (1.8\%). Importantly, 22 out of the 25 patients who developed motor deficits were reported by the study by Friedman and Bullitt [26] in 1987.

\section{IT Injections/Pumps with Analgesics}

Five studies including 255 patients (weighted mean age 63.2 years, male $50.2 \%$ ) were identified that implemented IT drug injections or pump insertions for resistant PHN [30-34]. All patients had used multiple pharmacological agents with very limited efficacy. The intervention was performed after a mean of 31.3 months from zoster onset. The mean patient-reported VAS scores were 7.3 and 4.6 before and after the procedure, respectively, while $41.8 \%$ of patients reported pain reduction $>50 \%$. More specifically, 108 patients received IT injections of methylprednisolone and lidocaine, and $87 \%$ of them reported pain reduction $>50 \%$. Of note, 1 study reported pain increase in all 6 patients who had the combined methylprednisolone and lidocaine IT injection [30]. On the other hand, only 8.5 and $6.2 \%$ of patients who received lidocaine and midazolam IT injections, respectively, reported pain reduction $>50 \%[30,31,34]$. A very high percentage of patients who received midazolam reported side effects including sedation (85.4\%), nausea and vomiting $(6.2 \%)$ as well as headache (4.1\%). Finally, only 1 small study of 4 patients inserted IT opioid pumps and reported a mean $41 \%$ pain reduction. However, 2 patients discontinued this therapy due to opioid-related side effects, depression and loss of efficacy.

\section{Caudalis DREZ Lesioning/Nucleotomy}

Five studies comprising 63 patients with resistant trigeminal PHN to medical therapy were identified from the literature review [23, 35-38]. Four studies performed caudalis DREZ lesioning/stereotactic nucleotomy-nucleotractotomy using a radiofrequency generator, and 1 study performed ultrasonic destruction of the nucleus caudalis 4 months to 4.5 years following zoster onset. This strategy achieved a high percentage of pain-free patients 
Table 2. Summarized pain scores before and after each neurosurgical procedure

\begin{tabular}{|c|c|c|c|c|c|c|c|}
\hline DREZ lesioning & 84 & 6 & 8.7 & 3.7 & 5 & 57.4 & 10.1 years \\
\hline SCS & 243 & 10 & 7.6 & 2.7 & 4.9 & 64.4 & 18.2 months \\
\hline IT medication & 255 & 5 & 7.3 & 4.6 & 2.7 & 36.9 & 31.3 months \\
\hline $\begin{array}{c}\text { Caudalis DREZ/ } \\
\text { nucleotomy }\end{array}$ & 60 & 4 & NA & $\begin{array}{l}78 \% \text { of patients } \\
\text { were pain-free }\end{array}$ & NA & NA & 35.8 months \\
\hline GKS & 19 & 2 & NA & NA & NA & $\begin{array}{l}47.3 \% \text { of patients } \\
\text { pain relief }>40 \%\end{array}$ & 29.6 months \\
\hline
\end{tabular}

$n$, number; VAS, visual analog scale; D, difference; FU, follow-up; NA, not available; DREZ, dorsal root entry zone; SCS, spinal cord stimulation; IT, intrathecal; DRG PRL, dorsal root ganglion pulsed radiofrequency lesioning; PN stim., peripheral nerve stimulation; GKS, gamma knife surgery.

(78.3\%, 47/60) during the follow-up (weighted mean 35.8 months). Chivukula et al. [23] reported a mean reduction of VAS from 7.3 to 3.7 following caudalis DREZ lesioning. Nevertheless, complications were mostly major; Hitchcock et al. [38] reported at least one of the following complications in all three patients (100\%) including ipsilateral facial and contralateral arm and body sensory loss. Also, the study by Grigoryan et al. [35] which used ultrasonic nucleus caudalis destruction reported complications in $75 \%(3 / 4)$ of patients including contralateral body sensory loss, ataxia and Brown-Sequard syndrome. Chivukula et al. [23] reported one incidence of neuropathy/radiculopathy among the three patients who had caudalis DREZ lesioning.

\section{DRG Pulsed Radiofrequency Lesioning}

Two studies including 69 patients (mean weighted age 68 years, $47.8 \%$ male) with nonresponsive PHN to medi$\mathrm{cal}$ therapy were found $[39,40]$. The average interval between zoster onset and the procedure was 21.9 months. Pulsed radiofrequency was performed in the thoracic, cervical and lumbar DRG in 69.6\% (48/69), 20.3\% (14/69) and $10.1 \%(7 / 69)$ of the patients. Patients had a mean pain score of 6.9 and after a mean follow-up of 3.5 months, it decreased to 2.7. No major complications were reported in the included studies suggesting the high safety profile of this procedure. One study reported a mean reduction of the morphine equivalent dose from $35.2 \mathrm{mg}$ before to $20 \mathrm{mg}$ after the procedure [40]. The study by Kim et al. [39] documented that $3 / 49(6.1 \%)$ patients discontinued all analgesic medication while the rest reduced the dose or maintained it to the pre-procedural levels.

\section{Peripheral Nerve Stimulation}

Three studies fulfilled the eligibility criteria of this review [41-43]. Overall 10 patients (age 57.3 years, 50\% male) who underwent peripheral nerve stimulation were identified. This procedure was performed $>6$ months from zoster onset at the trigeminal nerve $(60 \%, 6 / 10)$ or thoracic dermatome distribution $(40 \%, 4 / 10)$ after multiple treatment failures. The mean VAS score before and after the procedure was 8.6 and 2 , respectively, which was reported by 2 studies. All patients (100\%) reported a successful trial (pain relief $>50 \%$ ) during the first 2-14 days. After a mean follow-up of $>20$ months from the permanent pulse generator implantation, $80 \%(8 / 10)$ of the patients reported a satisfactory reduction $(>50 \%)$ in their pre-procedural pain. No major complications were reported.

\section{Gamma Knife Surgery}

Two studies reporting on gamma knife surgery for refractory trigeminal PHN with 19 patients (age 71.1 years, male $47.3 \%$ ) were identified $[2,44]$. The study by Urgosík et al. [44] targeted the trigeminal root entry zone while the study by Keep et al. [2] targeted the retrogasserian trigeminal nerve and the centromedial thalamic nucleus at the same radiosurgical session. Nine patients (47.3\%) reported pain relief $>40 \%$ during the 29.6 -month interval $[2,44]$. No complications from the radiosurgery were reported except for pain recurrence in 2 patients who initially demonstrated pain relief.

\section{Other Approaches with Sparse Data}

Several other neurosurgical procedures for resistant PHN have been published in single studies. A study of 3 
PHN patients reported that DBS of the nucleus ventralis posterior lateralis resulted in $1(33.3 \%)$ patient reporting successful DBS trial ( $>50 \%$ pain relief) [45]. In this patient, DBS did not maintain the analgesic effect at the 6-month follow-up interval. Brown and Pilitsis [46] published the results of motor cortex stimulation in 2 patients with recalcitrant trigeminal PHN. Both patients reported a significant pain relief (VAS decreased from 10 to 2 and 5 to 0 ) lasting several months following the procedure.

Tomycz et al. [47] suggested that cordotomy may be used for several pain syndromes and included 1 patient with resistant $\mathrm{PHN}$ for 3 years. This patient had a much improved pain outcome during the 5-week follow-up, but suffered transient leg weakness. A peripheral nerve surgery approach involving excision of peripheral nerves causing the recognizable $\mathrm{PHN}$ pain and implantation directly to the muscle was suggested by a study of 3 patients [48]. The authors concluded that all 3 patients were painfree during the mean 10-month follow-up period, without any procedure-related complications. One of these patients discontinued all pain medication by 2 weeks postoperatively.

A study of 9 patients who underwent percutaneous radiofrequency rhizotomy for trigeminal PHN showed that $88.8 \%(8 / 9)$ of patients had pain relief [49]. However, during the mean 25.1-month follow-up interval, 3 patients needed an additional procedure. Taub et al. [50] performed Gasserian ganglion stimulation in 4 patients and found that only 1 (25\%) elected to have a permanent implantation after the early 3-day trial. This patient did not achieve a sustainable pain relief $(>50 \%)$ during the chronic stimulation. Finally, 1 randomized trial was identified that implemented pulsed radiofrequency lesions to the intercostal nerve through a costal angle puncture [51]. This study showed that intercostal nerve radiofrequency lesions are associated with a higher pain-reducing effect and quality of life and lower use of tramadol compared to the sham group during the 6-month follow-up. However, the absolute reduction in VAS score was not provided for each group separately.

\section{Summary of Findings}

A total of 39 studies comprising 813 patients with refractory PHN were included. Ten studies with 243 patients reported use of SCS. The mean VAS score was 7.6 and 2.7 before and after the procedure. No serious complications were reported during the mean follow-up (18.2 months). DREZ lesioning was performed in 84 patients. The mean VAS score before and after the procedure was 8.7 and 3.7, respectively. One third of these patients re- ported a change in the character of pain from burning to aching/throbbing. During the postoperative period, $44.6 \%$ of patients developed motor deficits which were attributed to the procedure. Five studies investigated the effect of IT injections or pump insertions. The combined methylprednisolone and lidocaine IT injections demonstrated a very strong analgesic effect ( $87 \%$ of patients reported pain reduction $>50 \%$ ); however, results were inconsistent between the included studies. Other medications used individually included lidocaine, midazolam and opioids with limited efficacy. Caudalis DREZ lesioning/nucleotomy was reported in 5 studies with a total of 63 patients. This strategy showed that $78.3 \%$ of patients were pain-free during the 35.8-month mean long-term follow-up. However, serious motor and sensory deficits occurred in $75-100 \%$ of patients in these studies. DRG pulsed radiofrequency lesioning was reported by 2 studies (69 patients) and was associated with a notable pain reduction (mean VAS before and after was 6.9 and 2.7, respectively) without any major complications during the mean 3.5 months of follow-up. Peripheral nerve simulation was reported by 3 studies comprising 10 patients in total. This strategy was among the safest and most effective, demonstrating a VAS pain reduction from 8.6 to 2 without any complications during the follow-up $(>20$ months). Gamma knife surgery targeting the trigeminal nerve and/or centromedial nucleus was performed in 19 patients across 2 studies. No complications were reported, and $47.3 \%$ of patients reported pain relief $>40 \%$ during the mean 29.6-month interval.

\section{Discussion}

This was the first systematic literature review including all available neurosurgical approaches for the management of resistant PHN. In the current study we identified several different existing neurosurgical strategies, which are associated with various safety and efficacy profiles. SCS, DREZ lesioning and IT medication were the most frequently reported. Peripheral nerve stimulation, SCS and DRG pulsed radiofrequency lesioning achieved the highest pain reduction and were not associated with serious complications. Gamma knife surgery, spinal DREZ and caudalis DREZ lesioning/nucleotomy were efficacious but the latter two were associated with a high incidence of major postoperative complications.

The complex pathophysiology of PHN involving peripheral and central nervous system processes explains why there is a variety of potential pharmacological agents
62

Stereotact Funct Neurosurg 2019;97:55-65 DOI: $10.1159 / 000499476$
Texakalidis/Tora/Boulis 
and surgical procedures [10]. Specifically, first-line therapies including topical lidocaine patches, and oral gabapentin, pregabalin and tricyclic antidepressants have been proven safe and effective with only minimal systemic side effects. In cases where the analgesic effect is unsatisfactory, capsaicin patches, oral opioids, epidural injections and nerve blocks have been used with a varying efficacy [52]. Notably, in some patients even multiple pharmacological therapies will be unsuccessful to manage the debilitating pain of PHN. These patients are potential candidates for one of the neurosurgical approaches that the current study describes [52].

Moreover, DRG radiofrequency lesions seem to perform well without any associated complications; however, the mean follow-up of the studies was only 3.5 months which limited the capacity to detect chronic complications $[39,40]$. Our results demonstrate that peripheral nerve stimulation and SCS achieved an average of 76.5 and $64.4 \%$ pain reduction; those two procedures are less invasive among neurosurgical options, show promising results and are generally safe. We believe that they should be considered as a reliable first choice when recalcitrant PHN cases fail all other noninvasive treatments. Unfortunately, no comparative studies were identified in the literature search which limits our capability to suggest superiority of the one over the other strategy. The authors' personal experience with SCS in PHN, while limited, has not mirrored the results reported in this review. SCS might fail in cases where the DRG cells are destroyed; importantly however, the use of preoperative somatosensory evoked potentials can successfully predict whether SCS will be effective or not [53]. Further prospective and comparative studies with long-term follow-up intervals are needed in order to validate our findings and provide new insights into the neurosurgical management of PHN.

IT medications have been offered to $\mathrm{PHN}$ patients by means of injections and implanted pumps. Two randomized trials have been published comparing IT injections of methylprednisolone plus lidocaine versus lidocaine alone with extremely opposite results [30,34]. Kotani et al. [34] suggested that the combined methylprednisolone plus lidocaine outperformed the lidocaine alone injection; however, this trial's results have been questioned by several authors [52, 54]. The second trial by Rijsdijk et al. [30] found markedly different results despite the fact that the design differences were small except for slight modifications in the injected drug dosages; however, they could not identify the reason of their contradictory findings. Moreover, midazolam IT injections had a poor pain-reducing effect [31]. The only IT pump insertion

Neurosurgeons' Armamentarium for the Management of Refractory PHN study investigated the effect of opioid pumps in 4 patients, showing a promising short-term VAS score reduction; nevertheless, there are concerns in respect to the durability of its pain-alleviating effect and potentially intolerable opioid-related side effects [33].

Several studies have examined the effect of more invasive neurosurgical procedures for PHN patients including DREZ lesioning in the spinal cord and caudalis DREZ/ spinal trigeminal nucleotomy. In light of the major complications and morbidity that both procedures can impose, the authors suggest that they are reserved for the most recalcitrant PHN cases. Nevertheless, it should be mentioned that the majority of major complications reported in patients who received DREZ lesioning in the spinal cord came from the study by Friedmann et al. [26] published in 1987. Another important point is that DREZ is generally effective for allodynia/hyperalgesia whereas the aching or deep pain are commonly unrelieved [29, 55]. Of note, DREZ lesioning is a more challenging procedure when performed in the thoracic spinal cord due to its anatomy (more white matter compared to cervical/ lumbar spinal cord). In theory, this can increase the risk of motor deficits for thoracic PHN cases. However, future comparative studies with long-term follow-up intervals would be needed to validate that. Furthermore, stereotactic radiosurgery might have a potential role in the management algorithm of $\mathrm{PHN}$ patients given that approximately $50 \%$ of the patients reported pain relief $>40 \%$ during an average 30 -month follow-up interval. Importantly, patients who had gamma knife surgery did not report any major complication; nevertheless, these results stem from 2 retrospective studies including 19 patients only [2,44]. Finally, only sparse data from single studies were identified regarding other neurosurgical strategies including motor cortex stimulation, DBS, cordotomy, percutaneous radiofrequency rhizotomy, Gasserian ganglion stimulation, radiofrequency intercostal nerve lesioning and peripheral nerve implantation in the muscle. There is an evident need of prospectively designed comparative studies in order to help guide patients who suffer recalcitrant PHN towards the most efficacious and safe procedures. These studies should specifically report the conditions in which each technique works or does not work.

\section{Limitations}

To our knowledge, this is the first systematic literature review summarizing all available neurosurgical procedures for the management of resistant PHN. However, a number of limitations should be noted. First, the nonrandomized nature of these studies limits the generalizability 
of our results. Second, several of our included studies were case series including a small number of patients. Also, different centers, surgeons and older studies create heterogeneity in the current study. Last, some studies reported the mean VAS score reduction, whereas others reported the percentage of patients who achieved $>50 \%$ pain reduction; when possible both outcomes were synthesized, and this has caused discrepancies in the reported efficacy of each procedure.

\section{Conclusions}

The available neurosurgical approaches for recalcitrant PHN mostly include neuromodulatory and ablative procedures. It is suggested that patients with resistant PHN undergo minimally invasive, reversible, neuromodulatory procedures first, including SCS and peripheral nerve stimulation which have demonstrated promising postoperative analgesia, albeit in studies without head-tohead comparison. DRG radiofrequency lesioning should also be considered after the failure of less invasive neuromodulatory approaches. More invasive and irreversible neurosurgical procedures should be reserved for refractory cases, with consideration toward notable postoperative morbidity. However, it should be emphasized that the comparative efficacy of these neurosurgical procedures is yet to be investigated due to the total absence of comparative studies.

\section{Disclosure Statement}

This research did not receive any specific grant from funding agencies in the public, commercial or non-for-profit sectors.

\section{References}

1 Sampathkumar P, Drage LA, Martin DP. Herpes zoster (shingles) and postherpetic neuralgia. Mayo Clin Proc. 2009 Mar;84(3):274-80.

2 Keep MF, DeMare PA, Ashby LS. Gamma knife surgery for refractory postherpetic trigeminal neuralgia: targeting in one session both the retrogasserian trigeminal nerve and the centromedian nucleus of the thalamus. J Neurosurg. 2005 Jan;102(Special_Supplement Suppl):276-82.

3 Zin CS, Nissen LM, Smith MT, O'Callaghan JP, Moore BJ. An update on the pharmacological management of post-herpetic neuralgia and painful diabetic neuropathy. CNS Drugs. 2008;22(5):417-42.

4 Shannon HJ, Anderson J, Damle JS. Evidence for interventional procedures as an adjunct therapy in the treatment of shingles pain. Adv Skin Wound Care. 2012 Jun;25(6):276-84.

5 Kost RG, Straus SE. Postherpetic neuralgiapathogenesis, treatment, and prevention. $\mathrm{N}$ Engl J Med. 1996 Jul;335(1):32-42.

6 Wall PD. Neuropathic pain and injured nerve: central mechanisms. Br Med Bull. 1991 Jul;47(3):631-43.

7 Bennett GJ. Hypotheses on the pathogenesis of herpes zoster-associated pain. Ann Neurol. 1994;35(S1 Suppl):S38-41.

8 Fields HL, Rowbotham M, Baron R. Postherpetic neuralgia: irritable nociceptors and deafferentation. Neurobiol Dis. 1998 Oct;5(4): 209-27.

9 Philip A, Thakur R. Post herpetic neuralgia. J Palliat Med. 2011 Jun;14(6):765-73.
10 Argoff CE. Review of current guidelines on the care of postherpetic neuralgia. Postgrad Med. 2011 Sep;123(5):134-42.

11 Liberati A, Altman DG, Tetzlaff J, Mulrow C, Gøtzsche PC, Ioannidis JP, et al. The PRISMA statement for reporting systematic reviews and meta-analyses of studies that evaluate health care interventions: explanation and elaboration. J Clin Epidemiol. 2009; 62(10):e1-34.

12 Hozo SP, Djulbegovic B, Hozo I. Estimating the mean and variance from the median, range, and the size of a sample. BMC Med Res Methodol. 2005 Apr;5(1):13.

13 Chivukula S, Tempel ZJ, Weiner GM, Gande $\mathrm{AV}$, Chen CJ, Ding D, et al. Cervical and cervicomedullary spinal cord stimulation for chronic pain: efficacy and outcomes. Clin Neurol Neurosurg. 2014 Dec;127:33-41.

14 Yanamoto F, Murakawa K. The effects of temporary spinal cord stimulation (or spinal nerve root stimulation) on the management of early postherpetic neuralgia from one to six months of its onset. Neuromodulation. 2012 Mar-Apr;15(2):151-4.

15 Baek IY, Park JY, Kim HJ, Yoon JU, Byoen GJ, Kim KH. Spinal cord stimulation in the treatment of postherpetic neuralgia in patients with chronic kidney disease: a case series and review of the literature. Korean J Pain. 2011 Sep;24(3):154-7.

16 Iseki M, Morita Y, Nakamura Y, Ifuku M, Komatsu S. Efficacy of limited-duration spinal cord stimulation for subacute postherpetic neuralgia. Ann Acad Med Singapore. 2009 Nov;38(11):1004-6.
17 Moriyama K. Effect of temporary spinal cord stimulation on postherpetic neuralgia in the thoracic nerve area. Neuromodulation. 2009 Jan;12(1):39-43.

18 Kumar K, Toth C, Nath RK. Spinal cord stimulation for chronic pain in peripheral neuropathy. Surg Neurol. 1996 Oct;46(4):363-9.

19 Shimoji K, Hokari T, Kano T, Tomita M, Kimura R, Watanabe S, et al. Management of intractable pain with percutaneous epidural spinal cord stimulation: differences in painrelieving effects among diseases and sites of pain. Anesth Analg. 1993 Jul;77(1):110-6.

20 Meglio M, Cioni B, Rossi GF. Spinal cord stimulation in management of chronic pain. A 9-year experience. J Neurosurg. 1989 Apr; 70(4):519-24.

21 Harke H, Gretenkort P, Ladleif HU, Koester P, Rahman S. Spinal cord stimulation in postherpetic neuralgia and in acute herpes zoster pain [table of contents.]. Anesth Analg. 2002 Mar;94(3):694-700.

22 Sánchez-Ledesma MJ, García-March G, DiazCascajo P, Gómez-Moreta J, Broseta J. Spinal cord stimulation in deafferentation pain. Stereotact Funct Neurosurg. 1989;53(1):40-5.

23 Chivukula S, Tempel ZJ, Chen CJ, Shin SS, Gande AV, Moossy JJ. Spinal and Nucleus Caudalis Dorsal Root Entry Zone Lesioning for Chronic Pain: efficacy and Outcomes. World Neurosurg. 2015 Aug;84(2):494-504.

24 Liu MX, Zhong J, Zhu J, Xia L, Dou NN. Treatment of postherpetic neuralgia using DREZotomy guided by spinal cord stimulation. Stereotact Funct Neurosurg. 2015;93(3): 178-81. 
25 Young RF. Clinical experience with radiofrequency and laser DREZ lesions. J Neurosurg. 1990 May;72(5):715-20.

26 Friedman AH, Bullitt E. Dorsal root entry zone lesions in the treatment of pain following brachial plexus avulsion, spinal cord injury and herpes zoster. Appl Neurophysiol. 1988;51(2-5):164-9.

27 Rath SA, Seitz K, Soliman N, Kahamba JF, Antoniadis G, Richter HP. DREZ coagulations for deafferentation pain related to spinal and peripheral nerve lesions: indication and results of 79 consecutive procedures. Stereotact Funct Neurosurg. 1997;68(1-4 Pt 1): 161-7.

28 Kanpolat Y, Tuna H, Bozkurt M, Elhan AH. Spinal and nucleus caudalis dorsal root entry zone operations for chronic pain. Neurosurgery. 2008 Mar;62(3 Suppl 1):235-42.

29 Friedman AH, Nashold BS Jr. Dorsal root entry zone lesions for the treatment of postherpetic neuralgia. Neurosurgery. 1984 Dec; 15(6):969-70.

30 Rijsdijk M, van Wijck AJ, Meulenhoff PC, Kavelaars A, van der Tweel I, Kalkman CJ. No beneficial effect of intrathecal methylprednisolone acetate in postherpetic neuralgia patients. Eur J Pain. 2013 May;17(5):714-23.

31 Dureja GP, Usmani H, Khan M, Tahseen M, Jamal A. Efficacy of intrathecal midazolam with or without epidural methylprednisolone for management of post-herpetic neuralgia involving lumbosacral dermatomes. Pain Physician. 2010 May-Jun;13(3):213-21.

32 Kikuchi A, Kotani N, Sato T, Takamura K, Sakai I, Matsuki A. Comparative therapeutic evaluation of intrathecal versus epidural methylprednisolone for long-term analgesia in patients with intractable postherpetic neuralgia. Reg Anesth Pain Med. 1999 Jul-Aug; 24(4):287-93.

33 Zacest A, Anderson VC, Burchiel KJ. The glass half empty or half full - How effective are long-term intrathecal opioids in post-herpetic neuralgia? A case series and review of the literature. Neuromodulation. 2009 Jul;12(3): 219-23.

34 Kotani N, Kushikata T, Hashimoto H, Kimura $\mathrm{F}$, Muraoka $\mathrm{M}$, Yodono $\mathrm{M}$, et al. Intrathecal methylprednisolone for intractable postherpetic neuralgia. N Engl J Med. 2000 Nov; 343(21):1514-9.
35 Grigoryan YuA, Slavin KV, Ogleznev KYa. Ultrasonic lesion of the trigeminal nucleus caudalis for deafferentation facial pain. Acta Neurochir (Wien). 1994;131(3-4):229-35.

36 Schvarcz JR. Craniofacial postherpetic neuralgia managed by stereotactic spinal trigeminal nucleotomy. Acta Neurochir Suppl (Wien). 1989;46:62-4.

37 Teixeira MJ, Lepski G, Aguiar PH, Cescato VA, Rogano L, Alaminos AB. Bulbar trigeminal stereotactic nucleotractotomy for treatment of facial pain. Stereotact Funct Neurosurg. 2003;81(1-4):37-42.

38 Hitchock ER, Schvarcz JR. Stereotaxic trigeminal tractotomy for post-herpetic facial pain. J Neurosurg. 1972 Oct;37(4):412-7.

39 Kim YH, Lee CJ, Lee SC, Huh J, Nahm FS, Kim HZ, et al. Effect of pulsed radiofrequency for postherpetic neuralgia. Acta Anaesthesiol Scand. 2008 Sep;52(8):1140-3.

40 Kim ED, Lee YI, Park HJ. Comparison of efficacy of continuous epidural block and pulsed radiofrequency to the dorsal root ganglion for management of pain persisting beyond the acute phase of herpes zoster. PLoS One. 2017 Aug;12(8):e0183559.

41 Zibly Z, Sharma M, Shaw A, Deogaonkar M. Peripheral field stimulation for thoracic post herpetic neuropathic pain. Clin Neurol Neurosurg. 2014 Dec;127:101-5.

42 Jakobs M, Unterberg A, Treede RD, SchuhHofer S, Ahmadi R. Subcutaneous trigeminal nerve field stimulation for refractory trigeminal pain: a cohort analysis. Acta Neurochir (Wien). 2016 Sep;158(9):1767-74.

43 Johnson MD, Burchiel KJ. Peripheral stimulation for treatment of trigeminal postherpetic neuralgia and trigeminal posttraumatic neuropathic pain: a pilot study. Neurosurgery. 2004 Jul;55(1):135-41.

44 Urgosík D, Vymazal J, Vladyka V, Liscák R. Treatment of postherpetic trigeminal neuralgia with the gamma knife. J Neurosurg. 2000 Dec;93 Suppl 3:165-8.

45 Kumar K, Toth C, Nath RK. Deep brain stimulation for intractable pain: a 15-year experience. Neurosurgery. 1997 Apr;40(4):736-46.
46 Brown JA, Pilitsis JG. Motor cortex stimulation for central and neuropathic facial pain: a prospective study of 10 patients and observations of enhanced sensory and motor function during stimulation. Neurosurgery. 2005 Feb;56(2):290-7.

47 Tomycz L, Forbes J, Ladner T, Kahn E, Maris A, Neimat J, et al. Open thoracic cordotomy as a treatment option for severe, debilitating pain. J Neurol Surg A Cent Eur Neurosurg. 2014 Mar;75(2):126-32.

48 Ducic I, Felder JM 3rd. Peripheral nerve surgery for the treatment of postherpetic neuralgia. Ann Plast Surg. 2013 Oct;71(4):384-5.

49 Teixeira MJ, Siqueira SR, Almeida GM. Percutaneous radiofrequency rhizotomy and neurovascular decompression of the trigeminal nerve for the treatment of facial pain. Arq Neuropsiquiatr. 2006 Dec;64(4):983-9.

50 Taub E, Munz M, Tasker RR. Chronic electrical stimulation of the gasserian ganglion for the relief of pain in a series of 34 patients. J Neurosurg. 1997 Feb;86(2):197-202.

51 Ke M, Yinghui F, Yi J, Xeuhua H, Xiaoming L, Zhijun C, et al. Efficacy of pulsed radiofrequency in the treatment of thoracic postherpetic neuralgia from the angulus costae: a randomized, double-blinded, controlled trial. Pain Physician. 2013 Jan;16(1):15-25.

52 Dworkin RH, O'Connor AB, Kent J, Mackey SC, Raja SN, Stacey BR, et al.; International Association for the Study of Pain Neuropathic Pain Special Interest Group. Interventional management of neuropathic pain: NeuPSIG recommendations. Pain. 2013 Nov;154(11): 2249-61.

53 Sindou MP, Mertens P, Bendavid U, GarcíaLarrea L, Mauguière F. Predictive value of somatosensory evoked potentials for long-lasting pain relief after spinal cord stimulation: practical use for patient selection. Neurosurgery. 2003 Jun;52(6):1374-83.

54 Srinivasan B. Intrathecal methylprednisolone for postherpetic neuralgia. N Engl J Med. 2001 Mar;344(13): 1021.

55 Sindou M. Microsurgical DREZotomy (MDT) for pain, spasticity, and hyperactive bladder: a 20-year experience. Acta Neurochir (Wien). 1995;137(1-2):1-5.
Neurosurgeons' Armamentarium for the Management of Refractory PHN
Stereotact Funct Neurosurg 2019;97:55-65 DOI: $10.1159 / 000499476$ 